\title{
René Girad y la paradoja de la modernidad
}

\section{Luis Garagalza}

Universidad del País Vasco/Euskal Herriko Unibertsitatea

luis.garagalza@ehu.es

\section{Resumen}

El trabajo analiza la naturaleza paradójica de la modernidad occidental, por una parte, el Estado nacional, la ciencia y el mercado, las grandes instituciones modernas, se despliegan como dispositivos de pacificación para acabar con las guerras de religión que asolaron Europa al final de la edad media, pero, por otra parte, tales maquinarias creadas para acabar con el miedo crean a su vez nuevos implantes del miedo, la espantosa Shoah, que ponen en cuestión las premisas anteriores. El autor intenta comprender esta paradoja que late en el fondo de la modernidad observándola desde la perspectiva antropológica abierta por René Girard con sus estudios sobre el deseo mimético y el papel fundador que desempeña el sacrificio en los orígenes de la(s) cultura(s).

Palabras clave: violencia, lo sagrado, el efecto mimético, modernidad.

\section{Abstract. René Girard and the the Paradox of Modernity}

This paper takes into account the paradoxical nature of the western modernity which lies according to the author in that, on the one hand, the national State, the science and the market, as modern institutions, deploy themselves as instruments of pacification to end the wars of religion that devastate Europe at the end of the Middle Ages, but, on the other hand, such artefacts created to end the fear create, as unintended consequence, new implants of fear, such as the monstrous Shoah, which question the former premises. The author analyzes this paradox with the tools taken from the work of René Girard.

Key words: violence, the sacred, the mimetic effect, modernity.

\section{Sumario}
1. El deseo mimético
3. Modernidad y violencia

2. Mimetismo y violencia

La modernidad se concibió a sí misma y se presentó, entre otras cosas, como promesa y programa de la abolición paulatina, pero más rápida que lenta, de la violencia. El desarrollo paulatino y la aplicación práctica de la razón, la ciencia y la conciencia individual debería de ir acompañada de la disminución de la violencia y todos sus correlatos, el miedo, la injusticia, la pobreza, la igno- 
rancia, la sumisión... La decisión de romper con un pasado calificado de oscuro señalaba para la cultura occidental el inicio de una ascensión heroica hacia el ámbito de la luz para allanar los obstáculos que la constriñen, dejando así que se difunda por la totalidad del planeta.

Esta visión llenó de ilusión la historia europea durante los siglos XVIII y XIX, pero el siglo XX, casi desde su comienzo, se encargó de romperla en mil pedazos. En vez de ir disminuyendo el fenómeno de la violencia, Europa experimentaba entonces en su propio interior nuevas formas de conflicto, de agresión y de exterminio mucho más poderosas que las de los tiempos oscuros. Así, la posibilidad de liberar la energía nuclear utilizada en la bomba atómica se convierte en signo de una amenaza absolutamente nueva: la destrucción de la vida en todo el planeta.

Pues bien, vamos a intentar comprender esta paradoja que late en el fondo de la modernidad, observándola desde la perspectiva antropológica abierta por R. Girard con sus estudios sobre el deseo mimético y el papel fundador que desempeña el sacrificio en los orígenes de la(s) cultura(s).

\section{El deseo mimético}

R. Girard comenzó su labor investigadora en el campo de la crítica literaria. En su obra Mentira romántica y verdad novelesca ${ }^{1}$, descubre la importancia que tiene dentro del universo de la novela el deseo mimético. Se trata de un deseo que no surge espontáneamente de un sujeto autónomo que se dirige directamente hacia un objeto, sino que tiene un carácter triangular: está mediado por el deseo de otro, es deseo de lo que otro desea y porque el otro lo desea. Ese otro es, al mismo tiempo, modelo y rival, ya que es precisamente su deseo lo que convierte en valioso al objeto. Un tal deseo mimético, que podemos ver actuar ya en Tristán e Isolda, está también en el núcleo de la que suele ser considerada la primera novela moderna, Don Quijote de la Mancha. Alonso desea efectivamente lo que en su imaginación sería deseado por su mentor, el legendario caballero Amadís de Gaula, que le sirve de modelo. Es ese deseo mimético el que le hace ver a Dulcinea del Toboso en Aldonza Lorenzo, el yelmo de Mambrino en la vacía del barbero, los gigantes en los molinos de viento...

Pues bien, Girard va a distinguir dos tipos de relatos literarios que se distinguen por la relación que mantienen con el deseo mimético. El relato, y correlativamente también la actitud, que nuestro autor denomina "romántico» tendría como rasgo esencial el estar al servicio del mantenimiento de la ilusión de autonomía del sujeto deseante y pensante (ilusión que sería constitutiva, en su opinión, del hombre moderno), por lo que silencia u oculta la existencia del mediador en su intento de realzar la originalidad del protagonista. El relato que denomina "novelesco», por el contrario, es desenmascarador, revela el carácter mimético del deseo, dejando aparecer al mediador rival.

1. GIRARD, R. Mentira romántica y verdad novelesca. Barcelona: Anagrama, 1985. 
El genio novelesco, del que harían gala Cervantes, Stendhal, Dostoievski, Proust..., logra superar lenta y costosamente la mentira romántica para mostrar la verdad del deseo mimético (y sus correlatos: la envidia, la vanidad, el orgullo, la coquetería, el esnobismo...), haciendo que se extinga al ser reconocido como tal. Se alcanza así la experiencia del «temps retrouvé» (Proust), se nace a la humildad (Dostoievski) y se reconoce la propia locura (Cervantes): "Todos los planes de la existencia se invierten, todos los efectos del deseo metafísico son sustituidos por efectos contrarios. La mentira es remplazada por la verdad, la angustia por el recuerdo, la agitación por el reposo, el odio por el amor, la humillación por la humildad, el deseo según el otro por el deseo según Uno Mismo, la trascendencia desviada por la trascendencia vertical ${ }^{2}$.

Pues bien, al ser mirada desde la teoría del deseo mimético, la modernidad sería la consecuencia de un debilitamiento del universo tradicional que acaba con el desmoronamiento de la trascendencia vertical que le servía de fundamento. "Dios ha muerto y el hombre debe ocupar su lugar» ${ }^{3}$. El hombre moderno despierta condenado a ser libre: ya no hay Dios, ni rey, ni Señor que, desde fuera, desde arriba, desde la distancia, le indique lo que debe hacer, lo que ha de desear. Ha llegado a la mediación externa, en la que la distancia entre la esfera del mediador y la del sujeto es tal que esas dos esferas nunca entran en contacto. Las ilusiones de antaño son vistas ahora como supersticiones y el hombre moderno se enorgullece de rechazarlas, pero en ese mismo momento está cayendo en otra ilusión más perturbadora: la ilusión de autonomía.

\section{Mimetismo y violencia}

Girard sigue tirando del hilo descubierto en el estudio de la literatura moderna y elabora una teoría general de la cultura que se va a centrar en la noción de mimetismo y en el papel fundador que tiene la violencia sacrificial. A continuación, haremos un breve recorrido por esta compleja teoría girardiana para, desde ella, volver a abordar la paradoja de la modernidad, la cual va a comparecer ahora como un caso particular de lo que en general le ocurre a toda cultura: que se levanta sobre la enfermedad que debería impedir su existencia ${ }^{4}$.

Dado que el hombre es un ser cultural, no hay casi nada en su comportamiento que no sea aprendido, y el aprendizaje se basa en la imitación: en la

2. GIRARD, R., Mentira romántica y verdad novelesca. Barcelona: Anagrama, 1985, p. 265.

3. Girard, R., Mentira romántica y verdad novelesca. Barcelona: Anagrama, 1985, p. 56.

4. Cfr. Girard, R., Veo a Satán caer como el relámpago. Barcelona: Anagrama, 2002, p. 235. También el proceso de hominización se levanta sobre una paradoja de este tipo: lo más característico del ser humano es algo que, visto desde la perspectiva estrictamente biológica, resulta ser un obstáculo: el nacimiento prematuro, la indefensión y el largo periodo de dependencia de los niños (cfr. GIRARD, R. El misterio de nuestro mundo. Salamanca: Sígueme, 1982 , p. 97 y s. "Si lo descomponemos en elementos analizables, el proceso de hominización se revela constituido enteramente por fenómenos, cada uno de los cuales por sí sólo bastaría para hacerlo fracasar» ( p. 101). 
repetición de lo que hace el otro. El mimetismo resulta ser indispensable como sustento del aprendizaje y de la cultura, pero es al mismo tiempo algo sumamente peligroso, ya que genera rivalidad y conflicto al impulsar a apropiarse de lo que otro ha cogido.

El objeto queda cargado con un prestigio adicional sólo por el hecho de haber sido elegido por otro. El otro tiende, así, por el mero hecho de serlo, a convertirse en antagonista, y el antagonismo tiende a extenderse indefinidamente generando una situación de guerra de todos contra todos. El caos pesa como una amenaza constante sobre la cultura, ya que ésta rompe con la regulación instintiva del comportamiento de los animales. Y lo que impide el desencadenamiento y la generalización de la violencia es el hecho de que la mimesis puede, por decirlo, así, elevarse a un segundo grado: cabe, efectivamente, olvidar mi rivalidad personal y elegir como rival al antagonista del otro. La pulsión violenta resulta ser transferible: si no se satisface directamente, puede encontrar fácilmente una víctima de recambio.

Esta no fijación del deseo y de la violencia a un objeto determinado genera un proceso que tiende a retroalimentarse lo mismo que el anterior, por lo que puede llegar a ejercer el efecto contrario. Mientras que, en un primer momento, el contagio mimético generalizaba el conflicto, ahora va a establecerse la unanimidad por convergencia de todo el grupo contra un solo enemigo. Ese personaje que, sin ningún motivo o por cualquier motivo, se ha convertido en el foco que atrae las iras de todos, comparece como el responsable de todos los males que afectan a la comunidad y tan pronto como alguien arroje sobre él la primera piedra, el proceso mimético se desencadenará de nuevo y generará una lluvia de piedras que acabará con su vida, lo que restablecerá la tranquilidad en el grupo y dejará como testimonio una tumba con forma piramidal.

Girard pone mucho cuidado en observar que no se trata de un proceso que dependa de la voluntad de los miembros del grupo: «En las sociedades primitivas, el proceso no accede a la conciencia más que bajo la forma de lo sagrado. Incluso entre nosotros es sobre todo inconsciente" 5 . Esa fuerza que se desencadena y se impone arrolladoramente queda asociada a fuerzas de la naturaleza como tempestades, incendios, enfermedades, que actúan desde fuera imponiéndose sobre el hombre y se le presentan bajo la categoría de lo sagrado. Una vez que el sacrificio ha operado su efecto catártico restableciendo la calma y el orden dentro del grupo, la víctima propiciatoria, sobre la que se habían transferido los rencores, las rivalidades, las envidias y los deseos de venganza, cambia súbitamente de valoración y se presenta con una instancia benefactora, divina, que salva del caos a la comunidad, que la funda y la sostiene ${ }^{6}$. De este modo, cabría decir que la cultura, la institución, la sociedad, descansan sobre

5. GIRARD, R. Cuando empiezan a suceder estas cosas... Madrid: Encuentro, 1996, p. 31.

6. El mecanismo victimario tendría la estructura de una adicción: el adicto a una determinada sustancia obtiene de ella una calma aparente, que consiste sólo en la eliminación temporal del síndrome de abstinencia que ella misma provoca. 
un acto de violencia colectiva contra una víctima inocente. La cultura, toda cultura, tiene en principio un carácter sacrificial, está basada en la fascinación que ejerce la violencia, en lo que Girard denomina «la trascendencia de Satán» ${ }^{7}$.

Satán o el Diablo, es el que, sucesivamente, fomenta el desorden, el sembrador de escándalos, y el que en el paroxismo de las crisis por él provocadas, las resuelve de pronto expulsando al desorden. Satán expulsa a Satán por medio de las víctimas inocentes cuya condena siempre logra. Como señor que es del mecanismo victimario, lo es también de todas las culturas humanas que tienen como principio ese asesinato. En última instancia, es el Diablo, o, dicho con otras palabras, el mimetismo malo, el que está en el principio no ya de la cultura cainita, sino de todas las culturas humanas ${ }^{8}$.

La violencia sacrificial, que, en opinión de Girard, "constituye el auténtico corazón y el alma secreta de lo sagrado» ${ }^{9}$, tiene pues una doble dimensión: es al mismo tiempo destructiva y creadora, siembra el caos y genera el orden. Ciertamente, el orden generado por la violencia tiene un carácter precario, inestable, por lo que necesita ser periódicamente confirmado por el rito y el mito. El rito repite, bien que simbólicamente y, por tanto, de un modo atenuado, el acto fundador, conteniendo la amenaza de la violencia generalizada y protegiendo de ella a las comunidades. El mito, por su parte, se encarga de mantener la memoria de ese origen presentando el uso de la violencia como legítimo y necesario, es decir, afirmando la culpabilidad de la víctima. Lo religioso, lejos de ser algo superfluo o añadido desde fuera, una especie de "parásito", comparece así durkheimianamente como el núcleo de todo sistema social y el fundamento de las instituciones, que sólo de un modo paulatino se van secularizando, funcionalizando y racionalizando.

El mundo es entonces el reino de Satán. El poder de Satán reside en que se mantiene oculto, en que nadie conoce su secreto: el mecanismo victimario genera una representación mítica que oculta su naturaleza y engaña a los participantes impidiéndoles tomar conciencia de que han asesinado a una víctima inocente. En el mito, la víctima siempre es culpable. En virtud de la unanimidad y de la cohesión social alcanzada, la mentira queda sellada y consagrada como la verdad última.

Cabe pues decir, según el planteamiento de Girard, que el ser humano queda, por el hecho mismo de constituirse como humano, atrapado en el interior del círculo de la violencia, de la mentira, de la envidia, de la venganza y del odio. El ser humano es incapaz de descubrir por sí mismo el secreto de Satán, ya que el mecanismo victimario se oculta tras las representaciones y significaciones míticas que genera. «O bien se desencadena el mecanismo victimario y su unanimidad elimina a todos los testigos lúcidos, o bien no se desencadena, y los testigos permanecen lúcidos, pero no tienen nada que revelar» ${ }^{10}$.

7. Girard, R. Veo a Satán caer como el relámpago. Barcelona: Anagrama, 2002, p. 134.

8. Girard, R. Veo a Satán caer como el relámpago. Barcelona: Anagrama, 2002, p. 121.

9. GIRARD, R. La violencia y lo sagrado. Barcelona: Anagrama, 1995, p. 38.

10. Girard, R. Veo a Satán caer como el relámpago. Barcelona: Anagrama, 2002, p. 242. 
Estamos, pues, atrapados en esa trampa diabólica: vivimos, sin enterarnos, en un mundo estructurado por procesos miméticos y victimarios de los que nos beneficiamos. Somos cómplices sin saberlo. Cuando se topan con la víctima, todas las mitologías y las filosofías se lavan las manos, como hizo Pilatos. En este sentido, también las potestades, principados y estados, aun no siendo propiamente satánicos, serían de algún modo tributarios de Satán. De todas formas, afirma Girard, "no por ello pueden condenarse sin más, puesto que en un mundo en el que aún no se ha instaurado el Reino de Dios son indispensables para el mantenimiento del orden» ${ }^{11}$.

Sólo en la Biblia se inicia, según defiende Girard, la Revelación ${ }^{12}$. La Biblia abre un largo proceso de desacralización de la violencia en el que se va haciendo patente que la acusación lanzada por el mito era falsa y que la víctima era inocente. Contradiciendo la perspectiva mítica, la Biblia presenta a Abel, a José y a Job como víctimas que no habían hecho nada que justificara el trato que reciben. El Antiguo Testamento comienza así a desenmascarar la mentira de la violencia, la falsa trascendencia de Satán, prefigurando el definitivo triunfo de la Cruz que se consuma con la Encarnación, la muerte y la resurrección de Jesucristo. La Pasión de Jesús es muy parecida a los sacrificios que presentan los mitos: hay confabulación de todos contra uno, hay violencia colectiva y hay epifanía religiosa. Jesús muere como un chivo expiatorio, habiendo sido abandonado por sus amigos y hasta por su propio Padre, y lo es efectivamente para aquéllos que no creen en su inocencia: así Herodes y Pilatos, que estaban enemistados, se hacen amigos ${ }^{13}$.

Pero los Evangelios no relatan los hechos desde la perspectiva de los perseguidores, como hace el mito, sino desde la perspectiva del que padece la acusación falsa. Los Evangelios dicen la verdad: que Jesús era inocente. Ahora los que consideran a Jesús como Dios no son los integrantes de la multitud unánime que le acaba de condenar, sino una minoría disidente que no hace de él su chivo expiatorio. Lo decisivo aquí es la ruptura de la unanimidad, la liberación del influjo hipnótico que ejerce la masa. El proceso de revelación de la verdad iniciado en el Antiguo Testamento sólo puede completarse si el propio Dios asume, por amor a la humanidad, el papel de víctima: «A las divinidades míticas se opone un Dios que, en lugar de surgir del malentendido respecto a la víctima, asume voluntariamente el papel de víctima única y hace posible por primera vez la plena revelación de un mecanismo victimario» ${ }^{14}$.

11. GIRARD, R. Veo a Satán caer como el relámpago. Barcelona: Anagrama, 2002, p. 134.

12. El uso de la terminología religiosa por parte de Girard no es meramente casual ni tiene un carácter ilustrativo. Como él mismo declara, es un católico practicante. Aunque su madre era católica, el joven Girard no compartía sus creencias: «Decir que mi juventud fue cristiana, incluso moderadamente, sería una exageración» (GIRARD, R. Cuando empiezan a suceder estas cosas..., op. cit., p. 150). Pero en el transcurso de su investigación sobre la literatura moderna, en la que expone como los grandes novelistas logran descubrir el carácter triangular del deseo, sufrió una drástica conversión religiosa.

13. Lc. 22,12 .

14. Girard, R. Veo a Satán caer como el relámpago. Barcelona: Anagrama, 2002, p. 172. 


\section{Modernidad y violencia}

Pues bien, en opinión de Girard, la modernidad se levanta precisamente sobre ese proceso de revelación del mecanismo victimario iniciado por el cristianismo. La modernidad, entendida ahora en un sentido muy amplio como esa fase de la historia occidental que se inicia a finales del siglo XIV con el humanismo renacentista promotor de una lectura nueva de la Biblia, se caracteriza por su extrema ambivalencia. Es, por un lado, la época del espíritu crítico y de la actitud científica que, según apunta nuestro autor, se derivan de la denuncia de la violencia sacrificial que lleva a cabo el texto evangélico. Invirtiendo la tesis oficial que suele figurar en los manuales, según la cual sería el desarrollo de la ciencia lo que hace que cese la persecución de las brujas, Girard defiende que «la ciencia se ha impuesto a los hombres porque, por razones morales, religiosas, se ha cesado de perseguir a las brujas» ${ }^{15}$. La desacralización de la naturaleza y de la sociedad acarrea una toma de conciencia respecto al fenómeno de la violencia, y en virtud de esa nueva conciencia que se está desarrollando, los mecanismos victimarios se van debilitando, se tornan menos eficaces y cada vez resulta más difícil su renovación.

Ahora bien, la contrapartida de este debilitamiento de los mecanismos victimarios, que constituye el otro lado de la modernidad en virtud del cual hablamos de su ambivalencia, consiste en que el sujeto, al desprenderse de los férreos vínculos que le mantenían unido al cuerpo social sacralizado, tiende a caer en la ilusión del individualismo, a creerse y quererse autónomo a toda costa, original. En esto consiste lo que Girard llama la «mentira romántica». Rechaza la trascendencia vertical y cree que con ello se está librando de la necesidad de trascendencia.

Pero Girard defiende que la necesidad de trascendencia está arraigada en el ser humano de un modo tan profundo como la necesidad de imitación: es constitutiva de su ser. No basta por ello con rechazarla para suprimirla. La trascendencia que pierde su eficacia vertical se desvía hacia la horizontal, hacia lo humano. "A medida que el cielo se despuebla, lo sagrado refluye sobre la tierra» ${ }^{16}$. Ahora «los hombres se convierten en dioses los unos para los otros» ${ }^{17}$ y la mediación externa se convierte en mediación «interna». Florecen así lo que Stendhal llamó «sentimientos modernos»: la envidia, los celos y el odio impotente. La imitación de Cristo se convierte en imitación del prójimo. «Los hombres que no pueden contemplar la libertad, están expuestos a la angustia. Buscan un punto de apoyo en el cual fijar sus miradas [...] Los hombres desean según el otro para escapar al sentimiento de lo

15. GiRARD, R. Cuando empiezan a suceder estas cosas... Madrid: Encuentro, 1996, p. 67. "Aun cuando la institución cristiana fuera en algunos lugares el instrumento o el instigador de las cazas de brujas, el cristianismo es su verdadero destructor, pues hace ver a los hombres lo arbitrario de su desbocamiento persecutor que desemboca en la violencia» (GIRARD, R. Cuando empiezan a suceder estas cosas... Madrid: Encuentro, 1996, p. 17).

16. GIRARD, R. Mentira romántica y verdad novelesca. Barcelona: Anagrama, 1985, p. 61.

17. GIRARD, R. Mentira romántica y verdad novelesca. Barcelona: Anagrama, 1985, p. 53. 
particular; eligen unos dioses de recambio porque no pueden renunciar al infinito» ${ }^{18}$.

De este modo queda esbozada por Girard la paradoja constitutiva de la modernidad tal como comparece a través de la historia de la literatura: la liberación del deseo respecto al marco absoluto que lo encuadraba y lo definía en la visión tradicional del mundo genera una ilusión de autonomía y una pretensión de originalidad que oculta el hecho de que dicho deseo continúa siendo mimético, por lo que se convierte en el obstáculo que impide el auténtico deseo según uno mismo ${ }^{19}$. «El individuo moderno es eso que queda de la persona cuando las ideologías románticas han pasado por allí, es una idolatría de la autosuficiencia forzosamente engañosa, un voluntarismo antimimético que provoca, inmediatamente después, una repetición del mimetismo» ${ }^{20}$. Así pues, no se ha extinguido el carácter mimético del deseo: sigue actuando tras la ilusión de autonomía y tras la arrogancia prometeica del hombre moderno. Satán ha caído como el relámpago, su argucia ha sido desenmascarada, ha perdido el poder de expulsarse a sí mismo restableciendo el orden. "Como sus días están contados, Satán los aprovecha al máximo y muy literalmente, se desencadena ${ }^{21}$. Lejos de acabar con la violencia, la modernidad va a experimentar formas de conflicto, de agresión y de exterminio nunca antes conocidas.

18. GIRARD, R. Mentira romántica y verdad novelesca. Barcelona: Anagrama, 1985, p. 63.

19. Cfr. GiRARD, R. Mentira romántica y verdad novelesca. Barcelona: Anagrama, 1985, p. 265.

20. GIRARD, R. Cuando empiezan a suceder estas cosas... Madrid: Encuentro, 1996, p. 38.

21. Girard, R. Veo a Satán caer como el relámpago, o.c., p. 239. 